\title{
Laser additive manufacturing of multimaterial tool inserts: a simulation-based optimization study
}

Mohanty, Sankhya; Hattel, Jesper Henri

Published in:

Proceedings of Laser 3D Manufacturing IV

Link to article, DOI:

$10.1117 / 12.2253600$

Publication date:

2017

Document Version

Publisher's PDF, also known as Version of record

Link back to DTU Orbit

Citation (APA):

Mohanty, S., \& Hattel, J. H. (2017). Laser additive manufacturing of multimaterial tool inserts: a simulation-based optimization study. In B. Gu, H. Helvajian, A. Piqué, C. M. Dunsky, \& J. Liu (Eds.), Proceedings of Laser 3D Manufacturing IV (Vol. 10095). [100950G] SPIE - International Society for Optical Engineering. Proceedings of SPIE - The International Society for Optical Engineering https://doi.org/10.1117/12.2253600

\section{General rights}

Copyright and moral rights for the publications made accessible in the public portal are retained by the authors and/or other copyright owners and it is a condition of accessing publications that users recognise and abide by the legal requirements associated with these rights.

- Users may download and print one copy of any publication from the public portal for the purpose of private study or research.

- You may not further distribute the material or use it for any profit-making activity or commercial gain

- You may freely distribute the URL identifying the publication in the public portal 


\title{
Laser Additive Manufacturing of multimaterial tool inserts: A simulation-based optimization study
}

\author{
Sankhya Mohanty, Jesper Henri Hattel \\ Dept. of Mechanical Engineering, Technical University of Denmark, Produktionstorvet, \\ Kongens Lyngby, Denmark 2800
}

\begin{abstract}
Selective laser melting is fast evolving into an industrially applicable manufacturing process. While components produced from high-value materials, such as Ti6Al4V and Inconel 718 alloys, are already being produced, the processing of multi-material components still remains to be achieved by using laser additive manufacturing. The physical handling of multi-material in a SLM setup continues to be a primary challenge along with the selection of process parameters/plan to achieve the desired results - both challenges requiring considerable experimental undertakings. Consequently, numerical process modelling has been adopted towards tackling the latter challenge in an effective manner.

In this paper, a numerical simulation based optimization study is undertaken to enable selective laser melting of multi-material tool inserts. A standard copper specimen covered by a thin layer of nickel is chosen, over which a layer of steel has been deposited using cold-spraying technique, such as to protect the microstructure of $\mathrm{Ni}$ during selective laser melting. The process modelled thus entails additively manufacturing a steel tool insert around the multi-material specimen with a goal of achieving a dense product while preventing recrystallization in the Nickel layer. The process is simulated using a high-fidelity thermo-microstructural model with constant processing parameters to capture the effect on Nickel layer. Based on results, key structural and process parameters are identified, and subsequently an optimization study is conducted using evolutionary algorithms to determine the appropriate process parameter values as well as processing sequence. The optimized process plan is then used to manufacture real multi-material tool insert samples by selective laser melting.
\end{abstract}

Keywords: selective laser melting, multi-material tool inserts, multiscale 3DADI-2DCA modelling, thermomicrostructural analysis, multiobjective optimization, optimized process parameters

\section{INTRODUCTION}

Metal additive manufacturing has been an area of active research in the last decade, resulting in successful increase in technology readiness levels [1] [2] [3] for many of the processes falling under this umbrella term. Motivated by the increased application potential, and inspired from accessible published research in the more established associated fields of joining (e.g. welding) of dissimilar metals and manufacturing of functional graded materials, forays have already been made into additive manufacturing of multi-metal components by a few research groups [4] [5] [6] [7] [8]. However, additively manufactured multi-metal components are currently limited to research samples, primarily due to challenges in understanding, characterizing and controlling the involved manufacturing processes. While, typically, simulation studies are adopted in such scenarios for pushing the technological maturity, there exists no works on physics-based numerical modelling of the multimetal additive manufacturing process.

Thermo-metallurgical modelling of manufacturing processes, as such, is a well-established field of research. The application of these techniques towards modelling the microstructural evolution during selective laser melting is nonetheless still limited. However, several experimental studies can be found in literature having a focus on characterizing and predicting the microstructure during selective laser melting of materials [9] [10] [11] [12] [13]. Thermo-metallurgical modelling studies however exist for similar laser-based manufacturing

Laser 3D Manufacturing IV, edited by Bo Gu, Henry Helvajian, Alberto Piqué, Corey M. Dunsky,

Jian Liu, Proceedings of SPIE Vol 10095, 100950G · C 2017 SPIE

CCC code: $0277-786 \mathrm{X} / 17 / \$ 18 \cdot$ doi: $10.1117 / 12.2253600$

Proc. of SPIE Vol. 10095 100950G-1 
processes [14] [15]. In this work, a generic thermo-metallurgical model capable of modelling selective laser melting in a multi-material system has been documented. For the purpose of the optimization study, however, the thermodynamic interactions between different materials at the boundary layers has been neglected.

\section{THERMO-METALLURGICAL MODELLING}

\subsection{Theoretical Basis of Thermo-metallurgical Model}

The internal state variable approach [16] is well suited to the development of models for non-isothermal microstructural evolution. In general, a microstructure may be defined by different state variables such as grain size, volume fraction of grains, fraction of solid in solidification, etc. For the current case of solidification, two internal state variables can be used to describe the microstructure evolution -namely temperature and fraction of solid. The usage of these two state variables for modelling solidification microstructure is described below.

The interaction of the two state variables (temperature and fraction of solid) determines the type of microstructure formed during solidification. All grains produced during solidification are assumed to be equiaxed in nature, with columnar grains considered to be similar to elongated equiaxed grain.

The equiaxed solidification begins with nucleation in the regions of melt pool just below liquidus temperature and along the boundary of the melt pool. Although nucleation is a randomized phenomenon, statistical models exist for characterizing the overall nucleation in a melt pool. The Oldfield model [17] is most popular wherein the nucleation distribution is described by a Gaussian distribution. The grain density at a particular undercooling is given by

$$
n(\Delta T)=\int_{0}^{\Delta T} \frac{n_{\max }}{\Delta T_{\sigma} \sqrt{2 \pi}} \exp \left[-\frac{1}{2}\left(\frac{\Delta T^{\prime}-\Delta T_{N}}{\Delta T_{\sigma}}\right)^{2}\right] d \Delta T^{\prime}
$$

where $n_{\max }$ is the maximum possible nucleation density, $\Delta T_{N}$ is the mean undercooling and $\Delta T_{\sigma}$ is the standard deviation of the grain density distribution. Typically, these three parameters need to be obtained experimentally for a given material and condition.

Nucleation can occur in a homogeneous or heterogeneous manner; however the latter is much more common due to less energy requirements. The heterogeneous nucleation in the above model is assumed to be instantaneous and dependent on the characteristic undercooling. Once nucleated, the grains start to grow outwards. This results in the fraction of solid in the local melt pool area increasing, and there is corresponding release of latent heat of fusion which might increase the local temperature(this phenomenon is called recalescence). The grain nucleation is also random with respect to the orientation of the grain. Thus, to distinguish between different grains, a characteristic misorientation angle is attributed to each grain with respect to one of the principal direction.

Dendritic grain growth is assumed to be primarily driven by thermal undercooling and curvature undercooling. The kinetic undercooling and solute undercooling are ignored for the present work, though they are known to be important especially when in case of liquids with high Peclet number. The adopted grain growth model is similar to that described by Rappaz and Gandin [18].

\subsection{Modelling Framework}

The modelling of microstructure for selective laser melting is performed using a sequentially coupled 3DFVADI thermal model [19] and a 2D Cellular Automata microstructure model, the details of which can be found in prior works by the authors. To take into account the release of latent heat, equivalent specific heat capacity values are used during calculations. The prescribed temperature field thereby governs the undercooling occurring at each cell. As the thermal calculations are performed at a larger spatial and temporal discretization, 
the values are interpolated in the corresponding domains to match the requirements of the cellular automata. As a thumb rule, the spatial discretization of the CA model is near the order of the radius of dendritic tip, and the time resolution is such that the dendrite tip can only grow till the next adjacent cell at a maximum chosen undercooling.

\subsection{Thermo-metallurgical modelling of solidification}

As an example, the center line microstructure of a single melt track was modelled using the 3D-FVADI -2D Cellular Automata model for a single phase material. The parameters used for the thermal model are shown in Table 1 and the parameters for the microstructural model in Table 2.

Table 1 Parameters for thermal model

\begin{tabular}{ll}
\hline Parameters & Values \\
\hline Power & $120 \mathrm{~W}$ \\
FWHM & $100 \mathrm{e}-6 \mathrm{~m}$ \\
Powder bed porosity & 0.35 \\
Powder diameter & $30 \mathrm{e}-6 \mathrm{~m}$ \\
Scan Speed & $0.8 \mathrm{~m} / \mathrm{s}$ \\
Chamber Temperature & $200^{\circ} \mathrm{C}$ \\
\hline
\end{tabular}

Table 2 Parameters for microstructural model

\begin{tabular}{ll}
\hline Parameters & Values \\
\hline Maximum Nucleation Density $\left(\mathbf{n}_{\text {max }}\right)$ & $1 \mathrm{e} 16 \mathrm{~m}^{-3}$ \\
Mean Undercooling $\left(\Delta \mathbf{T}_{\boldsymbol{\mu}}\right)$ & $25 \mathrm{~K}$ \\
Standard nucleation density distribution $\left(\Delta \mathbf{T}_{\boldsymbol{\sigma}}\right)$ & $5 \mathrm{~K}$ \\
Number of grain misorientation states & 48 \\
Unit thermal undercooling $\left(\Delta \mathbf{H}_{\mathbf{f}} / \mathbf{C}_{\mathbf{p})}\right.$ & $523 \mathrm{~K}$ \\
\hline
\end{tabular}

The thermal model was used on a domain of $1 \mathrm{~mm}$ X $1 \mathrm{~mm}$ X $1.5 \mathrm{~mm}$ with elements of $10 \mu \mathrm{m}$ edge length in each direction. As the scan speed of the laser was high, the thermal model was solved at a time interval of $7.8125 \mathrm{e}-$ $7 \mathrm{~m} / \mathrm{s}$ which corresponds to $1 / 16^{\text {th }}$ of the time taken by center of laser beam to move from one element to the adjacent one. The 2D cellular automata model had square cells with edge length of $1.25 \mu \mathrm{m}$, thereby dividing 
each element from thermal model into 8 cells in the microstructural model. The time steps for the microstructural was selected as $2.232 \mathrm{e}-7$ based on the requirements for grain growth as discussed before.

Figure 1 shows the temperature field obtained from the thermal model at four time instances during the simulation of single melt track formation. The black rectangular borders shown on the figures correspond to the area selected for microstructure modelling using cellular automata. Figure $\mathbf{2}$ shows the solidification microstructure at the corresponding times. The grains are initially nucleated at the solid-liquid interface as can be seen in Figure 2 . Though simulated on a structured grid, the grains maintained their misorientation during growth which resembles real grain growth mechanism. Most of the grains are seen to be oriented at a large angle to the direction of laser movement (also commonly observed phenomena), which is a result of the grains growing normal to the solidification isotherm.
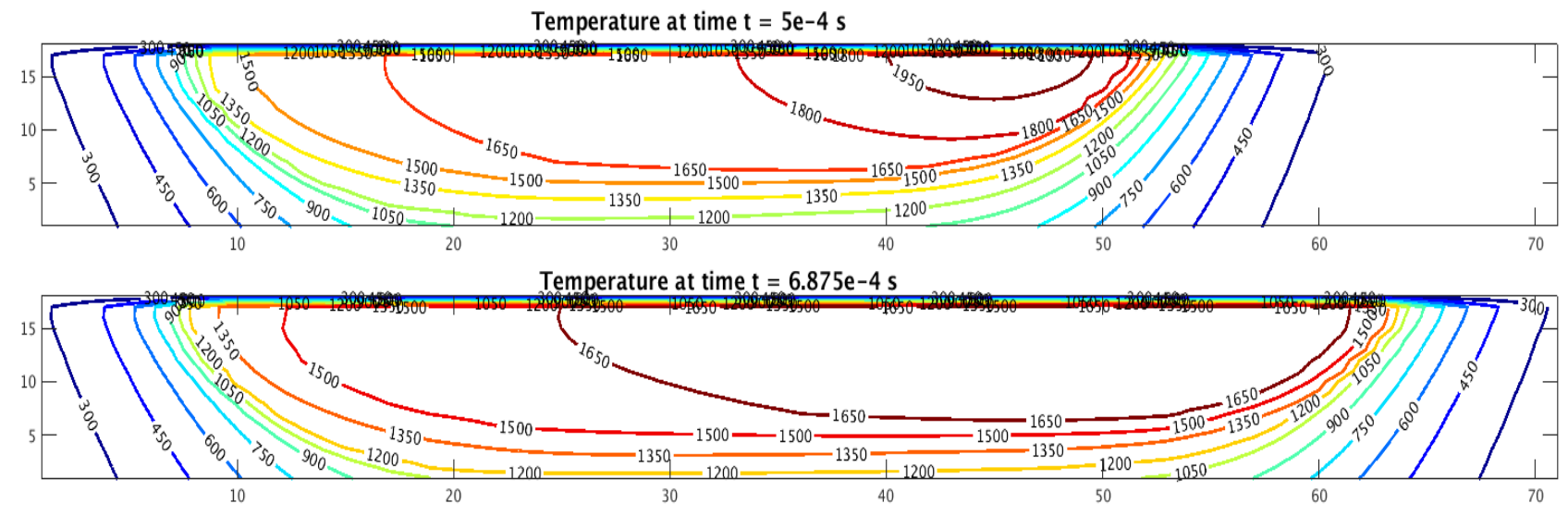

Temperature at time $\mathrm{t}=8.75 \mathrm{e}-4 \mathrm{~s}$

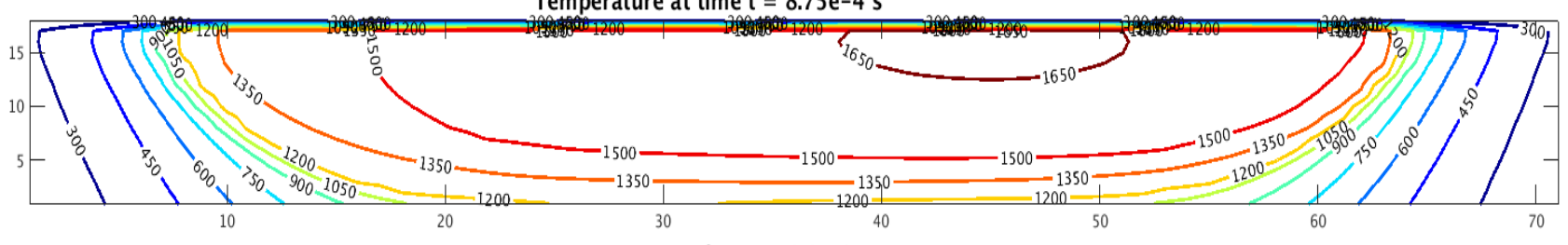

Temperature at time $\mathrm{t}=1.1 \mathrm{e}-3 \mathrm{~s}$

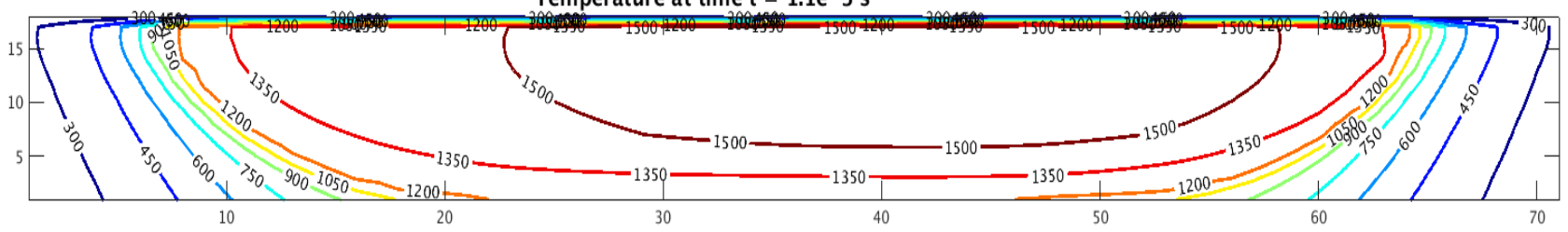

Figure 1 Centre-line temperatures at four time points during single track formation with SLM 

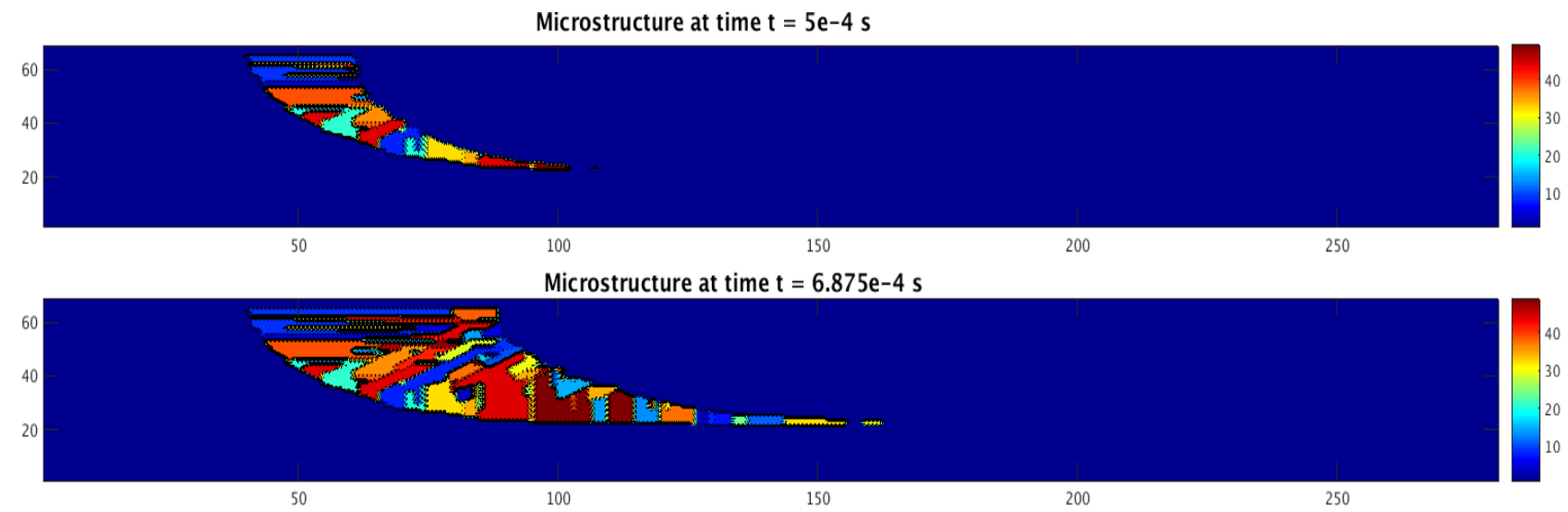

Microstructure at time $\mathrm{t}=8.75 \mathrm{e}-4 \mathrm{~s}$

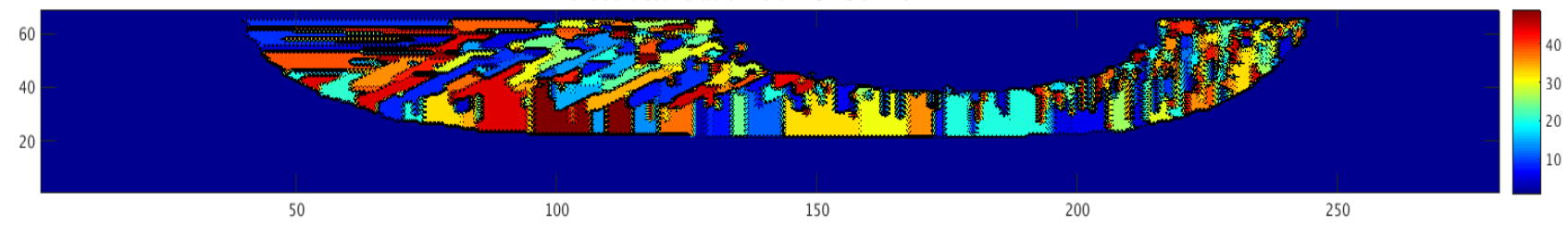

Microstructure at time $\mathrm{t}=1.1 \mathrm{e}-3 \mathrm{~s}$

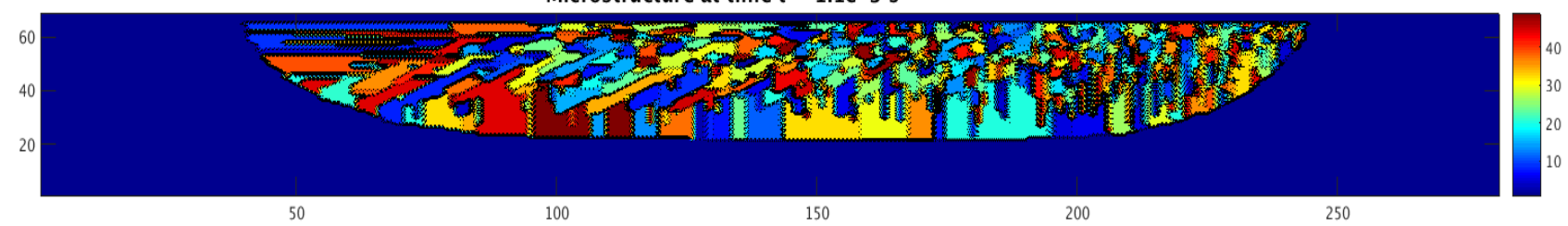

Figure 2 Evolution of centre-line microstructure at four time points during single track formation with SLM

For simulation of microstructures that can be validated against experimentally generated single tracks, the model would require several parameters which need to be determined experimentally such as the maximum nucleation density, the mean undercooling, the radius of unit thermal undercooling, etc. Given the appropriate parameters, however, the thermo-metallurgical model is able to predict the representative microstructure observed during selective laser melting.

\section{MODELLING BASED OPTIMIZATION OF MULTI-MATERIAL SLM}

\subsection{Description of Simulation Case}

For the current simulation-based study, the initial domain consists of a standard copper specimen of $15 \mathrm{~mm} \mathrm{X}$ $15 \mathrm{~mm}$ X $3.5 \mathrm{~mm}$ covered by a $500 \mu \mathrm{m}$ thick layer of Ni over which a further $500 \mu \mathrm{m}$ thick layer of $\mathrm{H} 13$ steel has been cold-sprayed. The model simulates addition of five $100 \mu \mathrm{m}$ thick layers of $\mathrm{H} 13$ steel on top of this domain wherein each layer is comprised of five parallel scan lines that are $100 \mu \mathrm{m}$ apart. Further, the component has been allowed to cool down for 5 seconds between each successive layer. The material properties used in the simulations for the three materials have been adopted from literature. 


\subsection{Typical Simulation Result}

As an example, selective laser melting of the above-described case has been performed with a laser peak power of $120 \mathrm{~W}$ and scanning speed of $0.8 \mathrm{~m} / \mathrm{s}$. The powder layer has been assumed to have a powder size distribution centred around $30 \mu \mathrm{m}$, and a powder bed porosity of $35 \%$ (i.e. $65 \%$ packing). The domain has an initial temperature of $200^{\circ} \mathrm{C}$, simulating pre-heating such as to reduce stress generation in overall component.

Figure 3 shows the temperature field in the longitudinal cross-section along the centre of the modelled domain during SLM of the third layer. Figure 3 also shows the copper, nickel and consolidated H13 regions of the domain at the same point of time. The temperature field indicates re-melting of the cold-sprayed H13 steel upto a few layers depth. Owing to the higher conductivity and heat capacity of the Nickel and Copper layers, the temperature is at a lower level in these regions. Figure $\mathbf{4}$ shows the temperature field in the transverse crosssection along the centre of the modelled domain at the same point of time.

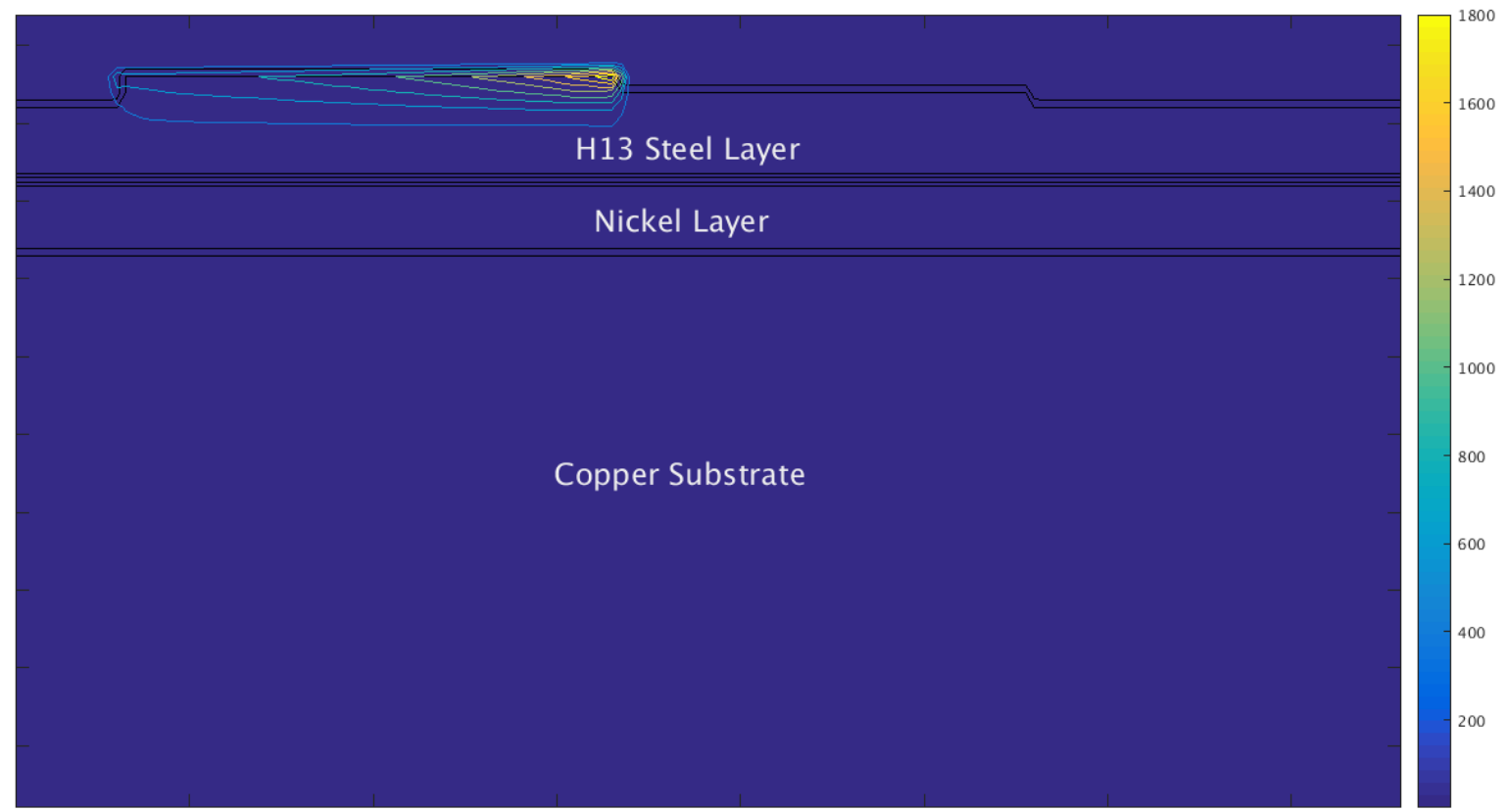

Figure 3 Temperature distribution in longitudinal cross-section of the sample during SLM of third layer of H13 steel (super-imposed on the material distribution) 


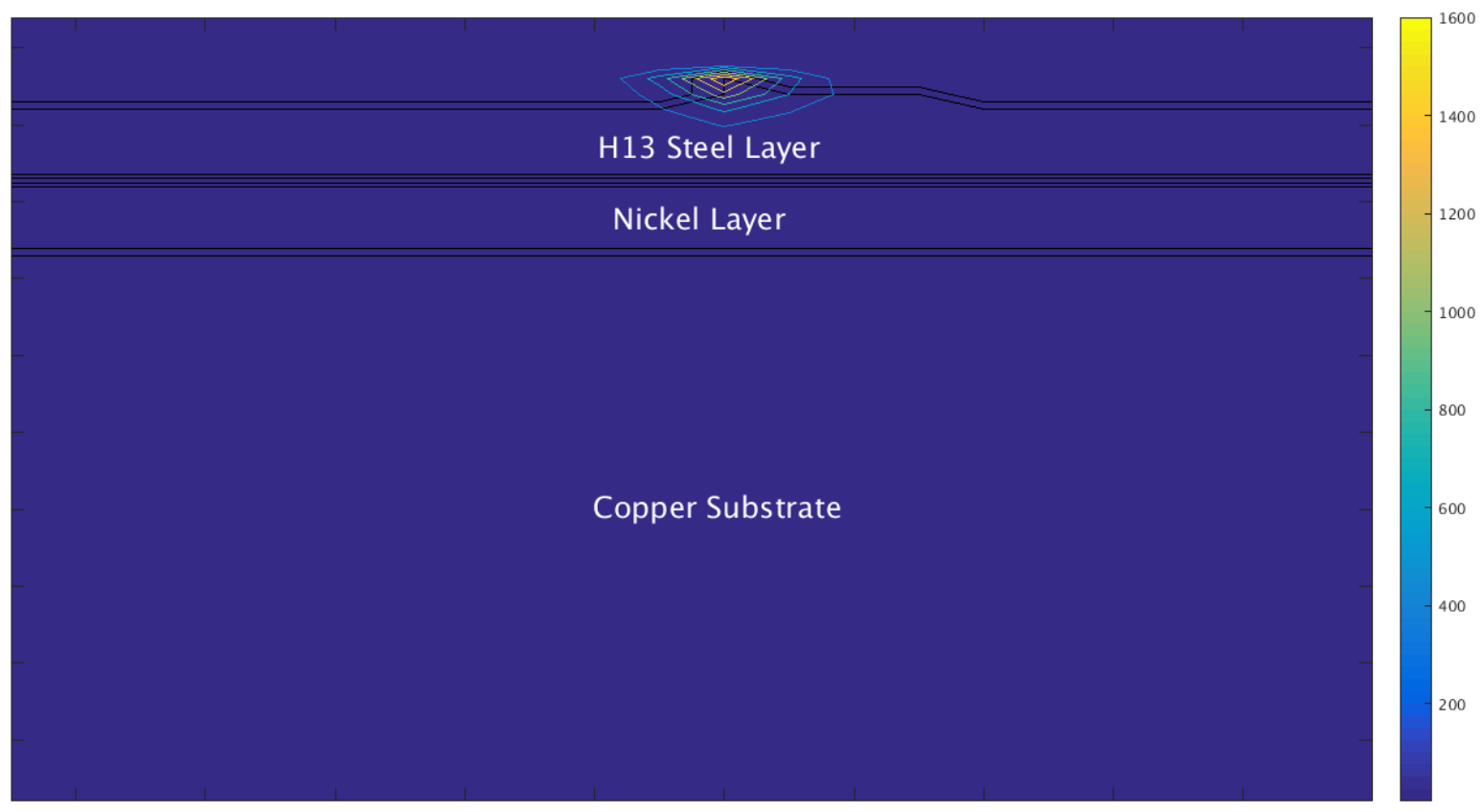

Figure 4 Temperature distribution in transverse cross-section of the sample during SLM of third layer of H13 steel (super-imposed on the material distribution)

\subsection{Description of Optimization Problem}

The simulated case offers four potentially conflicting objectives that need to be achieved. The first objective, as in standard SLM, involves the consolidation of the processed domain. For the purpose of this study, a consolidation of $95 \%$ is set as the minimum acceptable value. The second objective involves protection of the microstructure of Nickel i.e. minimizing/preventing thermally-activated recrystallization. In this optimization study, preference is given to the parameter values wherein no recrystallization occurs, but as a minimum the region within $200 \mu \mathrm{m}$ thickness from the Copper-Nickel interface should be recrystallization free. The third objective to minimize is the cooling time between processing of layers, which would determine the total processing time for a multi-layer component, while the fourth objective is to minimize the thickness of cold sprayed H13 steel layer.

For the current study, three parameters have been chosen that can be optimized to meet the objectives outlined above, namely the peak laser power, the thickness of the cold sprayed H13 steel layer and the cooling time between processing of each successive layer. The two processing parameters i.e. peak laser power and intermittent cooling time are constrained within $50 \mathrm{~W}$ to $150 \mathrm{~W}$ and $4 \mathrm{~s}$ to $10 \mathrm{~s}$ respectively. In this study, the time of processing and thickness of cold sprayed H13 layer are both an objective to minimize as well as a parameter being optimized. The thickness of the cold-sprayed H13 steel layer meant to protect the Nickel layers is set between $300 \mu \mathrm{m}$ to $1000 \mu \mathrm{m}$ - limited by the chosen cold-spraying process.

Genetic algorithm, more specifically NSGA-II, has been used to optimize the three chosen parameters with respect to the two outlined objectives. 


\section{RESULTS \& DISCUSSION}

Figure 5 shows the behavior of parameter sets corresponding to leading pareto front obtained by the optimization algorithm for consolidation and cold sprayed H13 layer thickness. Each point in the Figure 5 corresponds to a particular parameter set. As typically parameters might have interactions with respect to a particular objective (i.e. the effect on an objective upon changing two parameters together is not merely a summation of effects of changing the parameters one at a time), visualization for multi-objective optimization is best performed using pareto front as opposed to individual parameter-objective trends. Upon successful completion of optimization procedures, the results thus correspond to sets of parameter values that are nondominating i.e. changing a parameter to improve a particular objective criteria would result in degradation in the other objective criteria. The trend of the observed pareto front indicates that it is possible to minimize the thickness of cold sprayed H13 steel layer while improving the consolidation of the processed domain. However, all the points correspond to parameter sets which have been optimized with respect to four different objectives, and hence are non-dominating with respect to each other when all the objectives are considered.

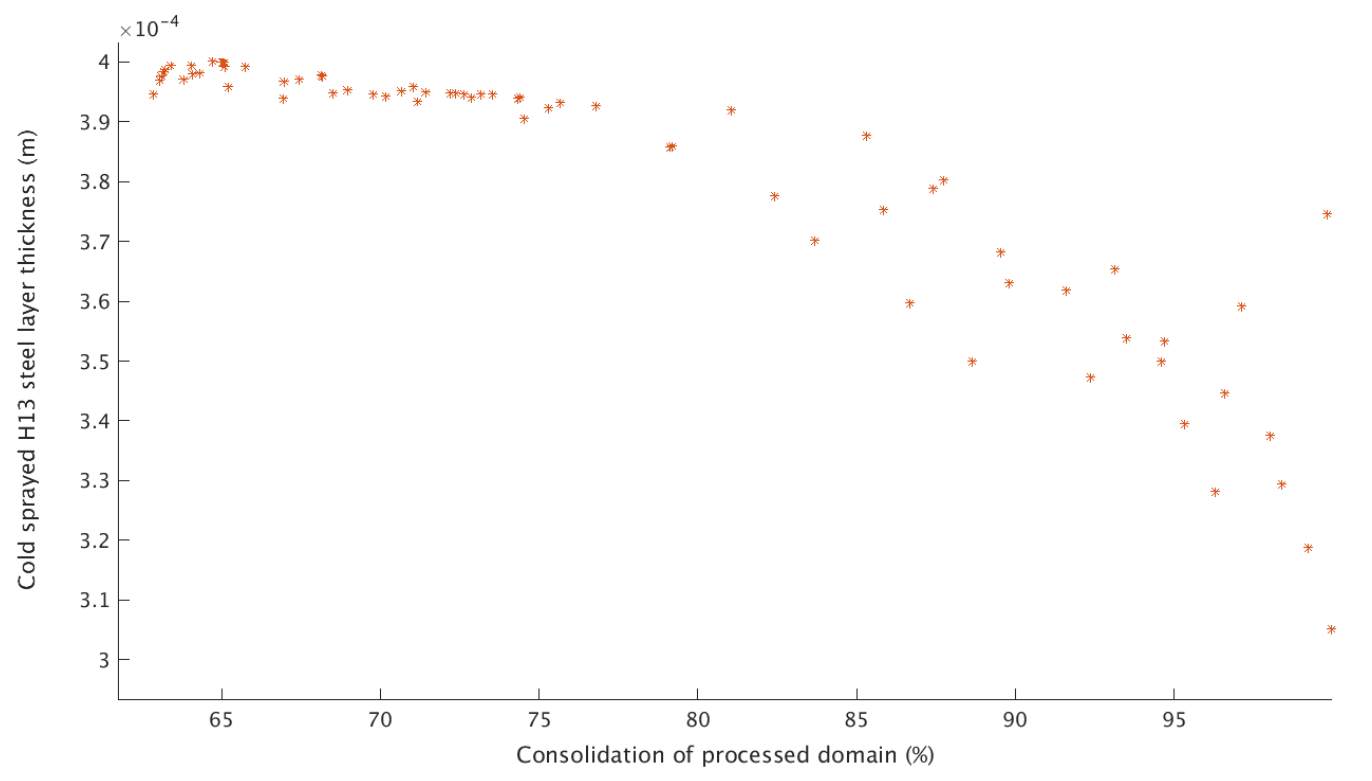

Figure 5 Pareto front predicted by optimization algorithm between thickness of cold-sprayed H13 layer and consolidation in the SLM processed region

The multi-objective optimization algorithm is not only able to predict optimized parameters with respect to each objective, but also arrange the parameter sets on non-dominated pareto fronts which provide equally optimum choices when considering all objectives of interest. Such information is particularly useful during process chain definition of the component.

\section{CONCLUSION}

A high-fidelity generic thermo-microstructural model capable of simulating nucleation and grain growth was developed and a specific case involving solidification microstructure was documented in this paper. The thermomicrostructural model composed of a sequentially coupled 3D ADI thermal model along with a 2D Cellular Automata based microstructural model. The model was used to simulate and later optimize selective laser melting of H13 steel tool inserts on a multi-material sample. Four conflicting objectives were identified and three parameters were chosen to be optimized using a multi-objective genetic algorithm. The resulting optimized parameter values have been selected for production of tool inserts, the results from which will be documented in future publications. 


\section{REFERENCES}

[1] W. Frazier, "Metal Additive Manufacturing: A Review," JMEPEG, vol. 23, pp. 1917-1928, 2014.

[2] A. Uriondo, M. Espero-Migues and S. Perinpanayagam, "The present and future of additive manufacturing in the aerospace sector: A review of important aspects," Proc. IMechE PartG: J Aerospace Engineering, vol. 229, pp. 2132-2147, 2015.

[3] D. Bourell, "Perspectives on Additive Manufacturing," Annu. Rev. Mater. Res., vol. 46, pp. 1$18,2016$.

[4] D. Hofmann, R. S, R. Otis and e. al, "Developing gradient metal alloys through radial deposition additive manufacturing," Nat Sci Rep, vol. 4, no. 5357, pp. 1-8, 2014.

[5] C. Theiler, T. Seefeld and G. Sepold, "Deposition of Gradient Metal Matrix composites by laser beam cladding," Geiger, M: Laser assisted net shape engineering 3. Bamberg: Meisenbach, pp. 421-430, 2001.

[6] O. Al-Jamal, S. Hinduja and L. Li, "Characteristics of bond in $\mathrm{Cu}-\mathrm{H} 13$ tool steel parts fabricated using SLM," CIRP Annals- Manufacturing Technology, vol. 57, pp. 239-242, 2008.

[7] C. Terrazas, S. Gaytan, D. Rodriguez, E. D, M. LE, F. Medina and R. Wicker, "Multi-material metallic structure fabrication using electron beam melting," Int J Adv Manuf Technology, 2013.

[8] H. Sahasrabudhe, R. Harrison, C. Carpenter and A. Bandyopadhyay, "Stainless steel to titanium bimetallic structure using LENS," Additive Manufacturing, vol. 5, pp. 1-8, 2015.

[9] C. Tuck, M. Simonelli and Y. Y. Tse, "Microstructure of Ti-6Al-4V produced by selective laser melting," Journal of Physics: Conference Series, vol. 371, p. 012084, 2012.

[10] C. Tuck, M. Simonelli and Y. Tse, "Microstructure and mechanical properties of Ti6Al4V fabricated by selective laser melting," 141st Annual Meeting and Exhibition-Supplemental Proceedings, vol. 1, pp. 863-870, 2012.

[11] M. T. C. Simonelli and Y. Tse, "Microstructure of Ti6Al4V produced by selective laser melting," in Electron Microscopy and Analysis Group Conference, 2011. 
[12] H. Li, B. Huang, F. Sun and S. Gong, "Microstructure and tensile properties of Ti6Al4V alloys fabricated by selective laser melting," Rare Metal Materials and Engineering, vol. 42, pp. 209-212, 2013.

[13] M. Simonelli, Y. Tse and C. Tuck, "On the texture formation of selective laser melted Ti6Al4V," Metallurgical and Materials Transactions a, vol. 45, no. 6, pp. 2863-2872, 2014.

[14] Z. Fan, T. Sparks, F. Liou, A. Jambunathan, Y. Bao, J. Ruan and W. Newkirk, "Numerical simulation of evolution of solidification microstructure in laser deposition," in Proceedings of the 18th Annual Solid Freeform Fabrication Symposium, 2007.

[15] J. Zhang, F. Liou, W. Seufzer, J. Newkirk, Z. Fan, H. Liu and T. Sparks, "Probabilistic simulation of solidification microstructure evolution during laser based metal deposition," in Proceedings of the 23rd Annual Solid Freeform Fabrication Symposium, Austin, Texas, 2013.

[16] Ø. Grong and H. Shercliff, "Microstructural modelling in metals processing," Progress in Materials Science, vol. 47, pp. 163-282, 2002.

[17] O. W, "A quantitative approach to casting solidification: Freezing of cast iron," Trans. Am. Soc. Metals, vol. 59, p. 945, 1966.

[18] M. Rappaz and A. Gandin, "A coupled finite element cellular automaton model for the prediction of dendritic structures in solidification processes," Acta Metall. Mater., vol. 42, no. 7, pp. 2233-2246, 1994.

[19] S. Mohanty and J. Hattel, "Numerical Model based Reliability Estimation of Selective Laser Melting Process," Physics Proceedia, vol. 56, pp. 379-389, 2014. 